\title{
Correction of Biapical Tibial Deformity by True Spherical Osteotomy, Modified Circular External Skeletal Fixation and Distraction Osteogenesis
}

\author{
Darby Walmsley ${ }^{1}$ Noel Fitzpatrick ${ }^{1}$ Cameron Black ${ }^{1}$ \\ ${ }^{1}$ Department of Orthopaedics and Neurology, Fitzpatrick Referrals, \\ Godalming, Surrey, United Kingdom \\ Address for correspondence Darby Walmsley, BVSC MRCVS, \\ Department of Orthopaedics and Neurology, Fitzpatrick Referrals, \\ Halfway Lane, Godalming, Surrey, GU7 2QQ, United Kingdom \\ VCOT Open 2019;2:e73-e80. \\ (e-mail: darby.walmsley@gmail.com).
}

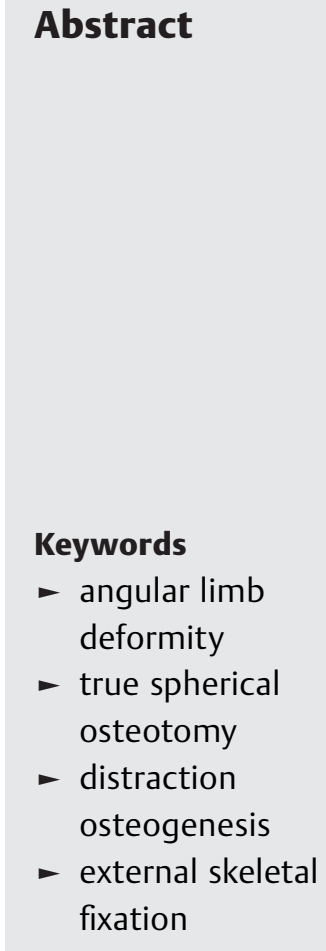

Objectives The aim of this study was to describe a case of biapical tibial deformity as a result of premature distal physeal closure corrected by true spherical osteotomy, circular external skeletal fixation and distraction osteogenesis.

Methods A 6-month-old male Labrador Retriever was presented for the evaluation and treatment of angular limb deformity of the left pelvic limb, with radiography and computed tomography revealing a multiplanar, biapical, compensatory tibial growth deformity, with marked distal tibial recurvatum and varus. A true spherical osteotomy was performed at the distal tibial centre of rotation of angulation (CORA), allowing for correction of the deformity in three planes, with a transverse osteotomy performed at the most proximal CORA. A circular external skeletal fixator was applied and distraction osteogenesis performed at the transverse osteotomy. Latency, distraction osteogenesis, and consolidation were performed over a 113-day period.

Results At frame removal, tibial length discrepancy improved from $16.8 \%$ to $0.6 \%$ and frontal plane varus angulation improvement from $20^{\circ}$ to $5^{\circ}$, when compared with the contralateral limb. Long-term evaluation revealed a satisfactory clinical and cosmetic outcome, judged by the clinician and owners, with force plate analysed symmetry index of the pelvic limb within reported normal limits.

Clinical significance To our knowledge this is the first case report illustrating the value of true spherical osteotomy for the treatment of an angular limb deformity when performed in combination with distraction osteogenesis in a canine pelvic limb.

\section{Introduction}

Angular limb deformities in dogs more commonly affect the antebrachium with pelvic limb deformities being less frequent. ${ }^{1}$ Premature cessation of pelvic limb growth due to physeal growth plate disturbances is reported in just $12 \%$ of injuries, with the tibia affected in $4.4 \%$ to $6.9 \%$ of physeal injuries. ${ }^{1-3}$ Eccentric medial closure of the distal tibial physis results in asymmetric growth of the distal tibia, growth retardation and pes varus deformation. ${ }^{1-3}$ The most common causes of premature physeal closure may be traumatic or developmental, with indication of a genetic aetiology of

received

October 30, 2018

accepted after revision

April 10, 2019
DOI https://doi.org/

10.1055/s-0039-1691781. ISSN 2625-2325. premature physeal closure in chondrodystrophic dogs. ${ }^{2,3}$ Other possible causes include nutrition, metabolic disorders, osteomyelitis or septic physitis or other developmental disorders such as skeletal dysplasia. ${ }^{2-7}$

Distal tibial varus angulation can result in shortening of the affected tibia with a 'bow-legged' appearance resulting from stifle abduction required to facilitate paw placement. ${ }^{8}$ Varus tibial deformity creates abnormal axial loading of the talocrural joint with potential for ligamentous injury, lameness and progressive osteoarthritis. ${ }^{9}$ Increased contact pressures at the tarsal joints lead to altered cartilage metabolism and (c) 2019 Georg Thieme Verlag KG Stuttgart . New York
License terms

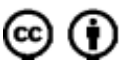


arthritis. Concurrently, stifle pathology including patellar luxation and cranial cruciate disease can be ascribed to pes varus. $^{10-12}$

Surgical management of distal tibial physeal closure in Dachshunds has been described by opening or closing wedge osteotomies stabilized with a locking plate, ${ }^{13}$ modified external skeletal fixation ${ }^{7}$ or hybrid external skeletal fixation. ${ }^{14}$ These procedures aim to realign proximal and distal articular surfaces into a normal frontal plane orientation. More recently, limb lengthening techniques such as distraction osteogenesis have gained popularity as a potential treatment for distal tibial physeal closure. ${ }^{15,16}$

When treating distal tibial valgus deformities, true spherical osteotomy has been reported in combination with a hinged circular external fixation. ${ }^{8}$ True spherical osteotomies enable correction of deformities with three rotational degrees of freedom: angulation, rotational and translational. ${ }^{17,18}$

To the authors' knowledge, the use of true spherical osteotomy has not been implemented for the treatment of distal tibial varus in adjunct with limb lengthening techniques. This report describes the use of true spherical osteotomy, modified circular external skeletal fixation and distraction osteogenesis for the treatment of a biapical angular limb deformity and limb length discrepancy in a Labrador puppy.

\section{Case Description}

\section{Examination}

A 6-month-old male Labrador Retriever $(13 \mathrm{~kg}$ ) was referred for the evaluation and treatment of angular limb deformity of the left pelvic limb. The dog was presented with a 3-month history of progressive left pelvic limb lameness exacerbated by increased activity levels, unresponsive to medical management or rest. There was no apparent history of trauma.

A grade 2/5 lameness of the left pelvic limb was apparent, with a visible limb length discrepancy and pelvic dip during loading. Varus angulation of the pes and distal tibia was seen at standing and ambulation, with recurvatum of the tibia palpable on examination. There were no signs of pain evident on manipulation.

\section{Diagnostic Imaging and Surgical Planning}

Orthogonal radiographic (craniocaudal and mediolateral projections) and computed tomographic (CT) assessment of the left tibia revealed a multiplanar (frontal, sagittal, torsional), biapical, compensatory tibial growth deformity, with marked distal tibial recurvatum and varus ( - Fig. 1, - Fig. 2A, - Fig. 2B). The left tibia measured $14.4 \mathrm{~cm}$ from the proximal joint orientation line, transecting the proximal tibial physis, to the distal joint orientation line, transecting the distal tibial physis. The contralateral tibia measured $17.3 \mathrm{~cm}$. The mechanical medial proximal tibial angle (MMPTA), mechanical medial distal tibial angle (mMDTA) were measured in the frontal plane with the mechanical caudal proximal tibial angle (mCdPTA) and mechanical cranial proximal tibial angle (mCrDTA) determined on the sagittal plane (-Table $\mathbf{1})$.

The centre of rotation of angulation (CORA) method and the mean mMDTA, MMPTA, mCdPTA and mCrDTA in Labrador

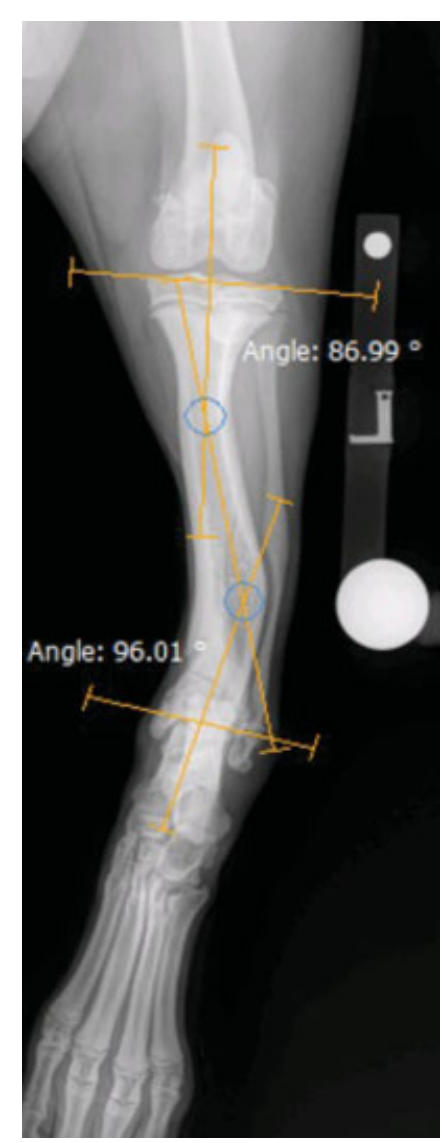

Fig. 1 Preoperative craniocaudal radiographic projection identifying a multiplanar, biapical, compensatory tibial growth deformity, with distal tibial recurvatum and varus. Angle measurements are representative of mean tibia joint orientation angles, as measured in Labrador Retrievers, 19,20 to identify centre of rotation of angulation locations.

Retrievers, as defined by Dismukes and colleagues, ${ }^{19,20}$ were utilized to identify the location for corrective osteotomies in the frontal and sagittal plane. A line bisecting the proximal joint orientation line and distal joint orientation line defined the anatomical axis, intersection of these lines identifying the CORA. Osteotomies were performed at the angulation correction axis and CORA co-located. Degree of correction was determined by comparison with contralateral limb ( $\mathbf{-}$ Table $\mathbf{1}$ ).

\section{Surgical Technique}

The dog was pre-medicated with a combination of methadone $(0.2 \mathrm{mg} / \mathrm{kg}$ intravenous [IV]; Comfortan, Dechra Veterinary Products, United Kingdom) and acepromazine ( $0.02 \mathrm{mg} / \mathrm{kg}$ IV; Elanco Animal Health, United Kingdom). Anaesthesia was induced with propofol ( $4 \mathrm{mg} / \mathrm{kg}$ IV; PropoFlo, Abbott Laboratories, North Chicago, Illinois, United States), maintained with isoflurane in oxygen. The left pelvic limb was clipped and prepared with chlorhexidine and an alcohol solution, and the patient positioned in dorsal recumbency. Owner consent was obtained prior to surgery.

Two $1.6 \mathrm{~mm}$ Kirschner wires were driven percutaneously mediolaterally and transcortically into the proximal tibia and fixed to a circular external skeletal fixation 5/8 ring (IMEX Veterinary, Inc. Longview, Texas, United States). Further 


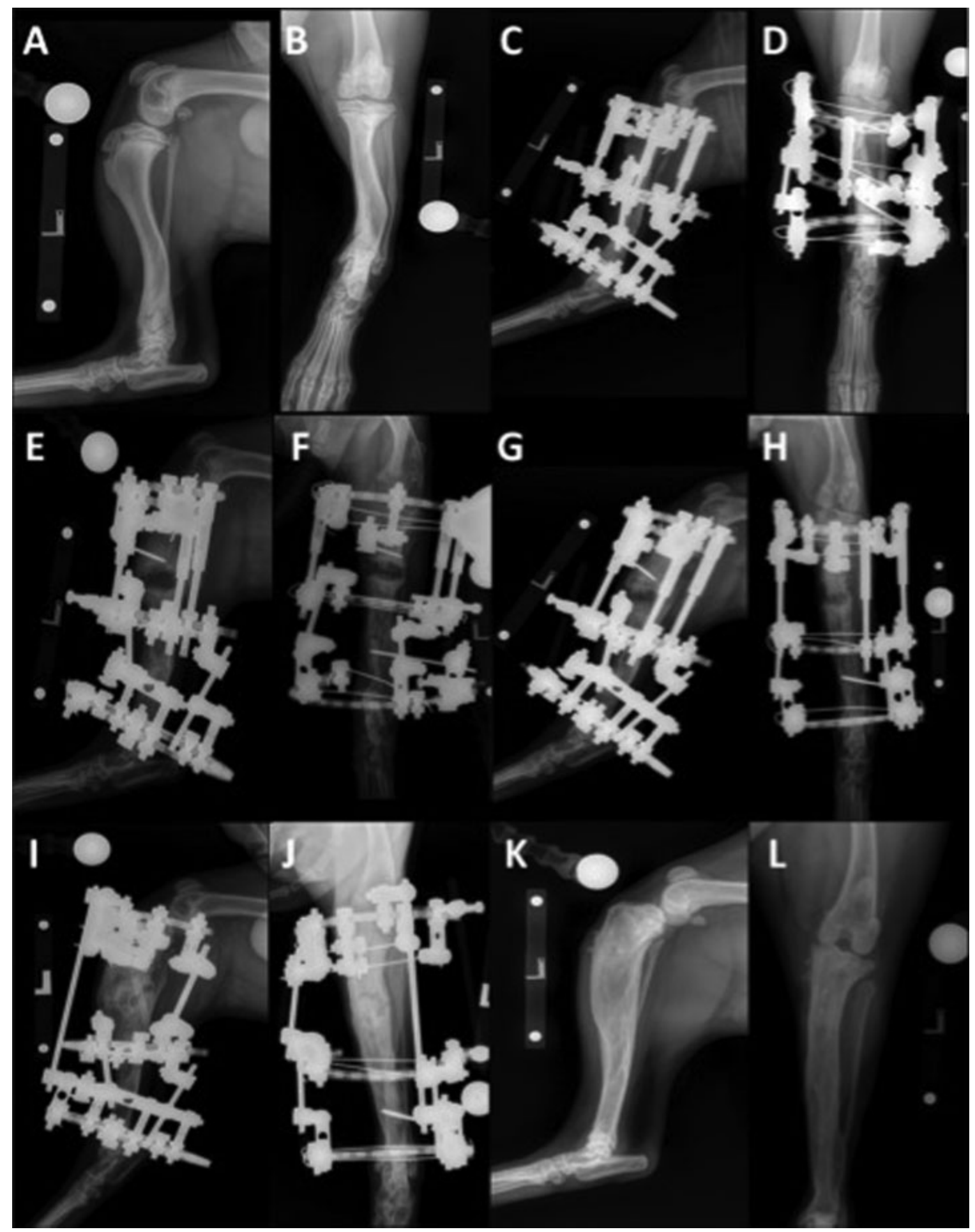

Fig. 2 Preoperative radiographic projections demonstrating tibial deformity (A, B). Immediate postoperative radiographic projections showing TSO and site of linear distraction (C, D). Initial evidence of cortical bridging of the osteotomy and intramedullary infill of regenerate bone (E, F). TSO site demonstrating radiographic healing by day $35(\mathrm{G}, \mathrm{H})$. Appropriate left pelvic limb tibial length was confirmed by orthogonal radiography and computed tomography at day 68 (I, J). Radiographic projections at 12 months postoperatively (K, L).

$1.6 \mathrm{~mm}$ Kirschner wires were inserted percutaneously into the mid-tibia and distal tibia. A $5 \mathrm{~cm}$ incision was then performed medially at the level of the mid-tibia to allow visualization and access to the bone. Correction by true spherical osteotomy was performed in the distal tibia at the level of the CORA ( - Fig. 3A), $4.9 \mathrm{~cm}$ proximal to the talocrural joint, utilizing an $18 \mathrm{~mm}$ dome blade (DOMESAW Matrix Orthopaedics Inc, Idaho, United States), resulting in apposed concave and convex surfaces. A transverse osteotomy was performed $5.2 \mathrm{~cm}$ distal to the tibial plateau, using an oscillating saw and osteotome (- Fig. 3B). A circular external skeletal fixation $5 / 8$ ring was fixed to the midtibial Kirschner wires and connected to the proximal ring by 
Table 1 Pre- and postoperative measurements of the operated limb

\begin{tabular}{|l|l|l|l|l|l|}
\hline Measurement & $\begin{array}{l}\text { Preoperative } \\
(\mathrm{L})\end{array}$ & $\begin{array}{l}\text { Preoperative } \\
(\mathrm{R})\end{array}$ & $\begin{array}{l}\text { Frame removal } \\
(\mathrm{L})\end{array}$ & $\begin{array}{l}\text { Frame removal } \\
(\mathrm{R})\end{array}$ & $\begin{array}{l}12 \text { months } \\
\text { postoperative (L) }\end{array}$ \\
\hline Frontal plane varus angulation & $20^{\circ}$ & $2^{\circ}$ & $5^{\circ}$ & $2^{\circ}$ & $5^{\circ}$ \\
\hline Frontal mMPTA & $95.4^{\circ}$ & $93.7^{\circ}$ & $105.4^{\circ}$ & $95.2^{\circ}$ & $104^{\circ}$ \\
\hline Frontal mMDTA & $76.1^{\circ}$ & $89.7^{\circ}$ & $85.3^{\circ}$ & $92.8^{\circ}$ & $86.5^{\circ}$ \\
\hline Sagittal mCdPTA & $69.3^{\circ}$ & $68.5^{\circ}$ & $60.1^{\circ}$ & $67.7^{\circ}$ & $61.2^{\circ}$ \\
\hline Sagittal mCrDTA & $85^{\circ}$ & $88.1^{\circ}$ & $86.2^{\circ}$ & $91.9^{\circ}$ & $86.1^{\circ}$ \\
\hline Tibial length & $144 \mathrm{~mm}$ & $173 \mathrm{~mm}$ & $190 \mathrm{~mm}$ & $191 \mathrm{~mm}$ & $192 \mathrm{~mm}$ \\
\hline
\end{tabular}

Abbreviations: mCdPTA, mechanical caudal proximal tibial angle; mCrPTA, mechanical cranial proximal tibial angle; mMDTA, mechanical medial distal tibial angle; mMPTA, mechanical medial proximal tibial angle.

(L), Left tibia; (R), Right tibia.

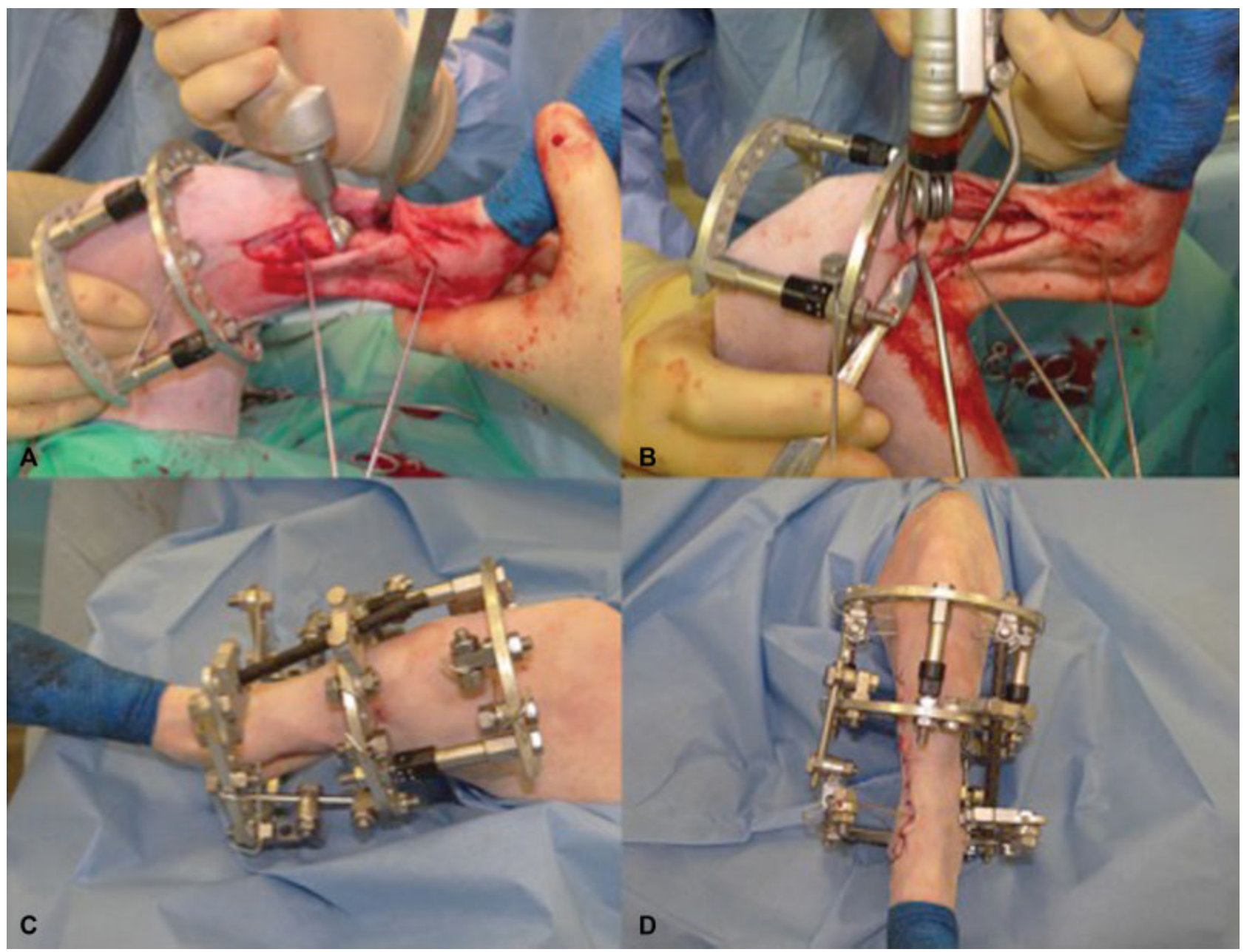

Fig. 3 Correction by TSO was performed in the distal tibia at the level of the centre of rotation of angulation (A). A transverse osteotomy was performed $5.2 \mathrm{~cm}$ distal to the tibial plateau, using an oscillating saw and osteotome (B). The frame constructs and linear motors were connected (C), and a routine surgical closure performed (D). Postoperative assessment of alignment and stifle and tarsus range motion were judged satisfactory. Sterile sponges were applied between the skin and frame to reduce postoperative swelling, with sterile swabs and bandage additionally applied to absorb discharge and act as an anti-microbial barrier.

three linear motors. Re-alignment of the middle and distal tibial segments at the level of the dome osteotomy was achieved. A stretch ring (IMEX Veterinary, Inc. Longview, Texas, United States) was placed distally, allowing a degree of flexion and extension through the hock, and connected to the middle tibial segment by threaded connecting rods. A $3 \mathrm{~mm}$ threaded external fixation pin was driven into both the proximal and distal segments for additional construct stability, engaging both cortices without penetrating the transcortex, and fixed onto the modified circular external skeletal fixation ( - Fig. 3C). Routine surgical closure of the incision was performed (-Fig. 3D, -Fig. 2C, -Fig. 2D). 


\section{Perioperative and Postoperative management}

Perioperative antibiotic therapy consisted of cefuroxime $(20 \mathrm{mg} / \mathrm{kg}$ IV; Zinacef, GlaxoSmithKline UK Ltd, Middlesex, United Kingdom) at least 30 minutes prior to first incision, and every 90 minutes during surgery thereafter, with cefalexin (20 mg/kg per-os every [q] $12 \mathrm{~h}$; Therios, Ceva Animal Health Ltd, Buckinghamshire, United Kingdom) then dispensed for 10 days postoperatively. Perioperative analgesia included an epidural of morphine $(0.15 \mathrm{mg} / \mathrm{kg}$; Hameln pharmaceuticals Itd, Gloucester, United Kingdom) and bupivacaine $(0.7 \mathrm{mg} / \mathrm{kg}$; AstraZeneca, Cheshire, United Kingdom), with methadone (0.2 $\mathrm{mg} / \mathrm{kg}$ IV every 4 hours; Comfortan, Dechra Veterinary Products, United Kingdom) administered intraoperatively as required. Postoperative analgesia consisted of methadone $(0.2 \mathrm{mg} / \mathrm{kg}$ IV q4h) and robenacoxib (1-2mg/kg orally every 24 hours; Onsior, Elanco, Eli Lilly and Company Ltd, Indiana, United States). Pain scores were performed every 4 hours with appropriate change from methadone to buprenorphine (0.01-0.02 mg/kg IV every 6 hours; Vetergesic; Ceva Animal Health Ltd, Buckinghamshire, United Kingdom). The patient was weight-bearing on the affected limb by day 5 postoperatively.

\section{Distraction Osteogenesis}

Following a latency period of 7 days, distraction osteogenesis was performed at a rate of $1 \mathrm{~mm}$ per day in increments of $0.25 \mathrm{~mm}$ every 6 hours, as per tension-stress shown to stimulate initial osteochondral ossification, ${ }^{21}$ at the site of the proximal osteotomy.

After 4 days of distraction (day 11), radiography revealed inadequate callostasis and bone formation, with a $7.4 \mathrm{~mm}$ gap present between the proximal and middle tibial segments. Distraction was reversed and osteotomy compressed. An additional Kirschner wire was driven into the proximal tibial segment under deep sedation. Distraction osteogenesis was re-initiated after 4 days at an index of $1 \mathrm{~mm}$ per day.

Radiographic and CT assessment at day 21 revealed adequate and progressive regenerate bone from apposing osseous surfaces with a fibrous interzone within the distraction gap (-Fig. 2E, - Fig. 2F). A 48-hour rest period was initiated prior to re-starting distraction ( - Table 1$)$.

Distraction index was then altered to a rate of $0.5 \mathrm{~mm}$ per day for 4 days, and then $0.75 \mathrm{~mm}$ per day at increments of $0.25 \mathrm{~mm}$ every 8 hours for 2 weeks (days 29-44) to promote further callostasis and encourage a degree of procallus organization during the distraction phase. Radiography and CT were repeated on days 26,28 and 33 , revealing cortical bridging of the osteotomy and intramedullary infill of regen-

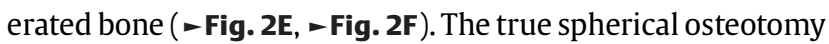
(TSO) site had healed by day 35 postoperatively ( - Fig. 2G, -Fig. 2H).

Appropriate left pelvic limb tibial length was confirmed by orthogonal radiography and CT at day 68 (- Fig. 2l, - Fig. 2]). Final alignment was made between proximal and distal segments, distraction apparatus removed and frame locked in static fixation. The patient was discharged for at-home management.

At day 113 , orthogonal radiography revealed adequate mineralization between bone segments, and the frame was removed. There were no signs of discomfort on manipulation of the limb, with satisfactory stifle and tarsal range of motion. An intermittent grade $1 / 5$ lameness was observed following frame removal. The patient was discharged with Tramadol ( $2 \mathrm{mg} / \mathrm{kg}$ per os every 12 hours) for 3 days, with no further medication required.

\section{Clinical Outcome}

The patient re-presented 12 months postoperatively. The patient was undertaking unrestricted off-lead activity. No lameness was apparent, and clinical examination of the affected limb did not reveal abnormal findings.

Force plate was used to measure ground reaction force percentages and limb symmetry, identifying left and right pelvic limb ground reaction force as 39 and $41 \%$ respectively and a symmetry index of 4.05 , within reported normal limits of healthy Labradors. ${ }^{22}$

Orthogonal radiography and CT demonstrated that tibial length had increased to $19.2 \mathrm{~cm}$, with frontal plane varus angulation, mMPTA, mMDTA, mCdPTA and mCrDTA measured (-Table 1) (-Fig. 2K, - Fig. 2L). Postoperative TPA measured $27.3^{\circ}$, within reported normal limits of a healthy Labrador Retriever TPA. ${ }^{23}$ There was no evidence of progressive stifle or tarsal osteoarthritis, cranial cruciate disease or patellar luxation.

\section{Discussion}

Correction of angular growth deformities has been extensively described in veterinary literature with a focus on deformities of the antebrachium and limited investigation into pelvic limb deformities. Investigation into chondrodystrophic dogs has provided more current recommendations for approach to treating tibial growth deformities. ${ }^{7,13,14}$ Described surgical treatment for pes varus deformities in such dogs have shown success in limb re-alignment., ${ }^{73,14}$ Biapically affected limbs have a higher likelihood of being more severely affected in the sagittal plane, and thus compounding their complexity. ${ }^{16,17}$

Realigning the mechanical axis and joint orientation of the stifle and tarsus requires a combination of angulation and translation. Conventional surgical treatments such as the simple transverse, open-wedge and closing wedge with internal fixation cannot accurately correct angulation and translation due to difference in the level of the CORA and the correction. ${ }^{16,17}$ The dome cut, according to Paley and others, ${ }^{18}$ is a cylindrical osteotomy which rotates around the central axis of a bone. Dome osteotomies allow the surgeon to pivot the bone segments in multiple planes to achieve appropriate alignment of the proximal and distal segments while maintaining osteotomy surface congruency avoiding translational deformities. ${ }^{17,18,24}$

True spherical osteotomies in human surgery show positive outcomes in the treatment of limb deformities ${ }^{25}$ and dysplastic conditions. ${ }^{26}$ Application of TSO in canine radial dome osteotomy combined with external coaptation achieved good-to-excellent postoperative function in $95 \%$ of dogs, and no visible long-term lameness in $73 \% .{ }^{27}$ True 
Table 2 Phases of distraction osteogenesis for the treatment of tibial deformity in a Labrador puppy

\begin{tabular}{|c|c|c|c|c|}
\hline Day & Phase & $\begin{array}{l}\text { Rate of } \\
\text { distraction }\end{array}$ & Radiography/CT & Frame alterations \\
\hline Day $1-7$ & Latency & - & - & - \\
\hline Day 8-11 & Distraction & $\begin{array}{l}1 \mathrm{~mm} / \text { day, } \\
0.25 \mathrm{~mm} \text { q6 }\end{array}$ & Inadequate callostasis (Day 11) & $\begin{array}{l}\text { Additional Kirschner wire added to } \\
\text { proximal tibial segment, distraction } \\
\text { reversed to compress osteotomy } \\
\text { site (Day } 11 \text { ) }\end{array}$ \\
\hline Day $12-15$ & Rest $^{a}$ & - & - & - \\
\hline Day $16-21$ & Distraction $^{\mathrm{b}}$ & $\begin{array}{l}1 \mathrm{~mm} / \text { day, } \\
0.25 \mathrm{~mm} \text { q6 }\end{array}$ & $\begin{array}{l}\text { Progressive regenerate bone origi- } \\
\text { nating from both osseous surfaces } \\
\text { (Day } 21 \text { ) }\end{array}$ & - \\
\hline Day $22-23$ & Rest & - & - & - \\
\hline Day 24-28 & Distraction & $\begin{array}{l}0.5 \mathrm{~mm} / \text { day, } \\
0.25 \mathrm{~mm} \text { q12 }\end{array}$ & $\begin{array}{l}\text { Continued intramedullary infill (Day } \\
26 \text {, Day 28) }\end{array}$ & $\begin{array}{l}\text { Straightened lateral aspect of } \\
\text { frame, adjusted medial clamp } \\
\text { (Day 28) }\end{array}$ \\
\hline Day 29-34 & Distraction & $\begin{array}{l}0.75 \mathrm{~mm} / \text { day, } \\
0.25 \mathrm{~mm} \mathrm{q} 8\end{array}$ & $\begin{array}{l}\text { Parallel columns of procallus ema- } \\
\text { nating from both cortical surfaces } \\
\text { (Day } 33 \text { ) }\end{array}$ & - \\
\hline Day $35-44$ & Distraction & $\begin{array}{l}0.75 \mathrm{~mm} / \text { day, } \\
0.25 \mathrm{~mm} \mathrm{q} 8\end{array}$ & $\begin{array}{l}\text { Radiographic healing of TSO site } \\
\text { (Day 35) }\end{array}$ & - \\
\hline Day 45 & Distraction $^{a}$ & $\begin{array}{l}0.75 \mathrm{~mm} / \text { day, } \\
0.25 \mathrm{~mm} \mathrm{q} 8\end{array}$ & $\begin{array}{l}\text { L Tibia }=16.3 \mathrm{~cm} \\
\text { R Tibia }=17.5 \mathrm{~cm} \\
\text { Satisfactory progression Satisfac- } \\
\text { tory limb alignment }\end{array}$ & $\begin{array}{l}\text { Tibial plateau transverse axis } \\
\text { slightly tilted medially, therefore } \\
\text { opened the medial side more. } \\
\text { Replaced three linear motors. } \\
\text { Removed distal connecting ele- } \\
\text { ment. Replaced wires and pins of } \\
\text { proximal segment due to discharge } \\
\text { at skin-pin interface }\end{array}$ \\
\hline Day 46-59 & Distraction & $\begin{array}{l}1 \mathrm{~mm} / \text { day, } \\
0.25 \mathrm{~mm} \text { q6 }\end{array}$ & - & - \\
\hline Day 60 & Distraction $^{\mathrm{b}}$ & $\begin{array}{l}1 \mathrm{~mm} / \mathrm{day} \\
0.25 \mathrm{~mm} \text { q6 }\end{array}$ & - & Linear motors replaced \\
\hline Day 61-68 & Distraction $^{a}$ & $\begin{array}{l}1 \mathrm{~mm} / \mathrm{day} \\
0.25 \mathrm{~mm} \text { q6 }\end{array}$ & $\begin{array}{l}\text { Procallus bridging cortical surfaces } \\
\text { both cranially and caudally } \\
\text { Appropriate L tibia length (Day } 68 \text { ) }\end{array}$ & $\begin{array}{l}\text { Linear motors removed. Manipula- } \\
\text { tion of soft intercalary distraction } \\
\text { zone to align proximal and distal } \\
\text { bone segments. Frame locked into } \\
\text { position (Day 68) }\end{array}$ \\
\hline Day 69-91 & Consolidation & - & & - \\
\hline Day $92-113$ & Consolidation $^{b}$ & - & $\begin{array}{l}\text { Satisfactory alignment and healing } \\
\text { Some degree of suboptimal trans- } \\
\text { verse axis alignment between } \\
\text { femorotibial and tibiotarsal joint }\end{array}$ & Frame removed (Day 113) \\
\hline
\end{tabular}

apatient discharged for at-home management.

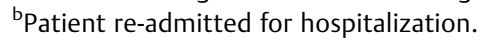

spherical osteotomies have demonstrated efficacy in intraarticular or juxta-articular CORAs due to the ability to offset the blade from the CORA. ${ }^{26}$

In this case, true spherical osteotomy was selected to avoid limb shortening and minimize the risk of transcortical fractures following previously described guidelines. ${ }^{28}$ Jaeger and colleagues ${ }^{29}$ reported the use of other modalities for correction of distal tibial valgus deformities in non-chondrodystrophic breeds, including medical management, segmental fibular ostectomy, closing wedge ostectomy, planar osteotomy and hinged circular external fixation and true spherical osteotomy with hinged circular fixation. Neither long-term outcome nor comparison of techniques was described. Choate and colleagues ${ }^{30}$ described the use of hinged circular external fixation, transverse osteotomy and concurrent angular and linear distraction osteogenesis for the treatment of tibial varus and valgus deformities as a result of traumatic premature physeal closure with sound results. Correction of biapical deformities utilizing external fixation and distraction osteogenesis has also been reported with successful outcomes. $^{17}$ 
The combination of modified circular external skeletal fixation and distraction osteogenesis allows for acute or progressive correction of angular, rotational and length discrepancies. ${ }^{6,16}$ Angular hinge assemblies and angular motor units provide precise postoperative adjustments while allowing controlled axial micromotion which stimulates callus formation and healing. ${ }^{16}$ Complications from distraction osteogenesis relate to elongation of soft tissue structures, with distraction exceeding $20 \%$ resulting in myotendinous and neural structures damage. ${ }^{21}$ The concept of latency duration in young dogs has been questioned, ${ }^{31}$ with an extended duration required for adequate pre-distraction callostasis in this case.

Frontal and sagittal tibial angle reference ranges in Labrador Retrievers have been reported. ${ }^{19,20}$ These ranges were used in combination with measurements of the patients' contralateral limb, and a decision was made to closely match measurements from the contralateral tibia for improved function and cosmesis. Tibial angle measurements are summarized (-Table 2). Further, the tibial length discrepancy had improved from 29 to $1 \mathrm{~mm}$ at the time of frame removal.

Both mMDTA and mCrDTA demonstrated correction progression towards the contralateral tibia values, with frontal plane varus angulation improvement from 20 to $5^{\circ}$. However, overcorrections were observed with both MMPTA and mCdPTA. The authors ascribe this to excessive medial tilting of the tibial plateau transverse axis throughout the distraction process despite attempts at correction at day 45 . This did not appear to increase the propensity for the development of cranial cruciate insufficiency, patellar luxation or stifle or tarsal osteoarthritis.

The patient demonstrated a satisfactory clinical outcome, equal pelvic limb weight-bearing, no overt pain on limb manipulation and an acceptable cosmetic outcome at 12 months postoperatively.

\section{Conclusion}

This report illustrates a successful functional and cosmetic outcome of a corrective procedure to realign a biapical tibial deformity by true spherical osteotomy, modified circular external skeletal fixation and distraction osteogenesis. To our knowledge, this is the first case report outlining the use of true spherical osteotomy for the treatment of angular limb deformity in combination with distraction osteogenesis in a canine pelvic limb.

\section{Author Contribution}

All authors contributed to conception of study, study design, acquisition of data and data analysis and interpretation. All authors also drafted, revised and approved the submitted manuscript.

\section{Funding \\ None.}

\section{Conflict of Interest}

None declared.

\section{References}

1 Ramadan RO, Vaughan LC. Disturbance in the growth of the tibia and femur in dogs. Vet Rec 1979;104(19):433-435

2 Marretta SM, Schrader SC. Physeal injuries in the dog: a review of 135 cases. J Am Vet Med Assoc 1983;182(07):708-710

3 Vaughan LC. Growth plate defects in dogs. Vet Rec 1976;98(10): 185-189

4 Ramadan RO, Vaughan LC. Premature closure of the distal ulnar growth plate in dogs-a review of 58 cases. J Small Anim Pract 1978;19(11):647-667

5 Carrig C, Merkley B, Mostosky U. Asynchronous growth of the canine radius and ulna: effects of different amounts of ulnar growth retardation. J Am Vet Radiol Society 1978;19:16-22

6 Marcellin-Little DJ, Ferretti A, Roe SC, DeYoung DJ. Hinged Ilizarov external fixation for correction of antebrachial deformities. Vet Surg 1998;27(03):231-245

7 Johnson SG, Hulse DA, Vangundy TE, Green RW. Corrective osteotomy for pes varus in the dachshund. Vet Surg 1989;18 (05):373-379

8 Fox D, Tomlinson J. Principles of angular limb deformity correction. In: Tobias K, Johnston S, eds., Small Animal Veterinary Surgery. 1st ed. St. Louis, MO: Elsevier Saunders; 2012:657-668

9 Kettelkamp DB, Hillberry BM, Murrish DE, Heck DA. Degenerative arthritis of the knee secondary to fracture malunion. Clin Orthop Relat Res 1988;(234):159-169

10 Slocum B, Slocum T. Tibial plateau levelling osteotomy for cranial cruciate ligament rupture. In Bojrab MJ, ed. Current Techniques in Small Animal Surgery. 4th ed. Baltimore, MD: Williams \& Wilkins; 1998:1187-1193

11 Morris E, Lipowitz AJ. Comparison of tibial plateau angles in dogs with and without cranial cruciate ligament injuries. J Am Vet Med Assoc 2001;218(03):363-366

12 Roush JK. Canine patellar luxation. Vet Clin North Am Small Anim Pract 1993;23(04):855-868

13 Petazzoni M, Nicetto T, Vezzoni A, Piras A, Palmer R. Treatment of pes varus using locking plate fixation in seven Dachshund dogs. Vet Comp Orthop Traumatol 2012;25(03):231-238

14 Radasch RM, Lewis DF, McDonald DE, Calfee EF, Barstad RD. Pes varus correction in Dachshunds using a hybrid external fixator. Vet Surg 2008;37(01):71-81

15 Lewis D, Radasch R, Beale B, et al. Initial clinical experience with the IMEX circular external skeletal fixation system. Part II: use in bone lengthening and correction of angular and rotational deformities. Vet Comp Orthop Traumatol 1999;12:118-127

16 Kwan TW, Marcellin-Little DJ, Harrysson OL. Correction of biapical radial deformities by use of bi-level hinged circular external fixation and distraction osteogenesis in 13 dogs. Vet Surg 2014; 43(03):316-329

17 Fox DB, Tomlinson JL, Cook JL, Breshears LM. Principles of uniapical and biapical radial deformity correction using dome osteotomies and the center of rotation of angulation methodology in dogs. Vet Surg 2006;35(01):67-77

18 Paley D. Osteotomy concepts and frontal plane realignment. In: Paley D, Herzenberg JE, eds. Principles of Deformity Correction. Berlin: Springer-Verlag; 2003:99-154

19 Dismukes DI, Tomlinson JL, Fox DB, Cook JL, Song KJ. Radiographic measurement of the proximal and distal mechanical joint angles in the canine tibia. Vet Surg 2007;36(07):699-704

20 Dismukes DI, Tomlinson JL, Fox DB, Cook JL, Witsberger TH. Radiographic measurement of canine tibial angles in the sagittal plane. Vet Surg 2008;37(03):300-305

21 Ilizarov GA. The tension-stress effect on the genesis and growth of tissues: Part II. The influence of the rate and frequency of distraction. Clin Orthop Relat Res 1989;(239):263-285

22 Bockstahler B, Tichy A, Aigner P. Compensatory load redistribution in Labrador Retrievers when carrying different weightsa non-randomized prospective trial. BMC Vet Res 2016; $12: 92-103$ 
23 Reif U, Probst CW. Comparison of tibial plateau angles in normal and cranial cruciate deficient stifles of Labrador Retrievers. Vet Surg 2003;32(04):385-389

24 Sikes R, Olds R, Renegar W, et al. Dome osteotomy for the correction of long bone malunions: case reports and discussion of surgical technique. J Am Hosp Assoc 1986;22:221-226

25 Hahn SB, Choi YR, Kang HJ. Corrective dome osteotomy for cubitus varus and valgus in adults. J Shoulder Elbow Surg 2009;18(01):38-43

26 Hu QS, Ul-Haq R, Park KS, Yoon TR, Lee KB. Dome osteotomy of the pelvis using a modified trochanteric osteotomy for acetabular dysplasia. Int Orthop 2012;36(01):9-15

27 MacDonald JM, Matthiesen D. Treatment of forelimb growth plate deformity in 11 dogs by radial dome osteotomy and external coaptation. Vet Surg 1991;20(06):402-408
28 Fitzpatrick N, Nikolaou C, Ochoa J, et al. True spherical dome osteotomy using a novel blade design in a dog with anebrachial growth deformity: Planning and execution of technique. In: Proceedings of Veterinary Orthopedic Society 38th Annual Conference; Snowmass, Colorado; February 20-27, 2011:22

29 Jaeger GH, Marcellin-Little DJ, Ferretti A. Morphology and correction of distal tibial valgus deformities. J Small Anim Pract 2007;48 (12):678-682

30 Choate C, Lewis S, Kim E, Cerdea CW. Use of hinged circular fixator constructs for the correction of crural deformities in three dogs. Aus Vet J 2012;90(07):256-263

31 Tuohy JL, Marcellin-Little DJ, Griffith EH. Durations of bone consolidation and external fixation after distraction osteogenesis in dogs. Vet Surg 2014;43(08):903-911 